\title{
Morphometric analysis of follicular dynamics in pregnant and pseudopregnant rats
}

\author{
P. Osman \\ Department of Anatomy, Medical Faculty, Erasmus University, P.O. Box 1738, 3000 Dr Rotterdam, \\ The Netherlands
}

\begin{abstract}
Summary. Morphometric analysis of the follicle population $\geq 100 \times 10^{5} \mu \mathrm{m}^{3}$ or a mean diameter of $\geq 275 \mu \mathrm{m}$ and assessment of the rate of atresia in ovaries of pregnant and pseudopregnant rats revealed no evidence for the presence of rhythmic follicular maturation during the prolonged dioestrous period. During the first 4-5 days of the dioestrous period, follicles developed to preovulatory size (volume class 5 , i.e. $\geq 1000 \times 10^{5} \mu \mathrm{m}^{3}=$ diam. $\geq 576 \mu \mathrm{m}$ ) reaching the normal number of ovulating follicles in cyclic animals in pregnant rats, but only half that number in pseudopregnant rats. These follicles collapsed on the 5 th to 8 th days of the dioestrous period and full numbers of preovulatory follicles were not found thereafter until the end of pregnancy and pseudopregnancy. Follicles of smaller sizes (classes 1-4: 100-999 $\times 10^{5} \mu \mathrm{m}^{3}$ ), however, were present throughout the prolonged dioestrous period. The rate of atresia in the follicle population had increased by the 2 nd day and remained from then on at $26.5 \pm 4.5 \%$ in the pregnant and $34.3 \pm 1.9 \%$ in the pseudopregnant rats. Atretic follicles in the advanced stages of atresia, mostly derived from follicles of classes 1-3, persisted and accumulated at the end of the dioestrous period.

The continuous presence of follicles and the constant rate of atresia during the dioestrous period indicate continuous follicular replacements and refute the idea of follicular quiescence during pregnancy and pseudopregnancy. Copulation and electrical stimulation of the cervix seemed to reduce the formation of the new crop of follicles the next morning and the pool of small antral follicles normally maintained after oestrus in cyclic animals. Nevertheless, the smaller crop and pool of follicles seemed able to provide a sufficient number of preovulatory follicles at the end of pregnancy and a sufficient number of ovulations at the end of pseudopregnancy.
\end{abstract}

\section{Introduction}

Follicular development has been studied in rats during pregnancy (Greenwald, 1966) and pseudopregnancy (Welschen et al., 1975). During these prolonged dioestrous states inhibition of oestrus and ovulation occurs although enough evidence has been found to assume that follicular growth continues (Asami, 1920; Evans \& Swezy, 1931; Ingram, 1962; Schwartz \& Tally, 1968; Pedersen \& Peters, 1971; Greenwald, 1978). However, there is still no agreement about the presence or absence of cyclic follicular maturation during these dioestrous periods. Attempts have been made to detect a cyclic follicular rhythm during pregnancy (e.g. Evans \& Swezy, 1931; Bujard, 1953), but the evidence is not very convincing (Greenwald, 1978). Since the rate of atresia, i.e. the proportion of follicles which start to degenerate within a follicle population, can be assessed and has proved to be useful in the analysis of follicular dynamics in cyclic rats (Osman, 1985), it can perhaps be used, together with follicular counts, to analyse follicular dynamics during pregnancy and pseudopregnancy. Moreover, the fate of atretic follicles can also be studied during these 
prolonged dioestrous states, when no rapid ovarian changes occur. These changes occurring at pro-oestrus and oestrus in cyclic animals (Osman, 1975) were assumed to be the cause of the elimination of follicles in the advanced stages of atresia by compression (Osman, 1985). It is also of interest to investigate the fate of the pool of small antral follicles from the preceding cycle which is maintained and produces the follicles destined to ovulate in the next cycle in cyclic animals (Osman, 1985). Since no ovulation occurs during pregnancy and pseudopregnancy, those follicles will probably become atretic in the prolonged dioestrous period. How then are the antral follicles that ovulate at the end of pregnancy or pseudopregnancy formed? The present study concerns the problem of cyclic follicular maturation, the fate of atretic follicles and the development of antral follicles during pregnancy and pseudopregnancy in rats.

\section{Materials and Methods}

Female rats of the R-Amsterdam strain, a Wistar substrain, 2-3 months old and weighing $170-220 \mathrm{~g}$, were used. They were kept in a temperature-controlled room $\left(22-24^{\circ} \mathrm{C}\right)$ under controlled light conditions: $14 \mathrm{~h}$ light and $10 \mathrm{~h}$ darkness with the middle of the light period at 12:00 $\mathrm{h}$. The rats received standard dry pellets and tap water ad libitum. Daily vaginal smears were made at 10:00 h. Only animals displaying at least two consecutive 5-day cycles were used.

Pregnancy was induced in the animals by caging 2 females together with a fertile male during vaginal pro-oestrus until the next morning. The day on which a vaginal plug or spermatozoa in the vaginal smear was observed was designated as Day 1 of pregnancy. Pregnancy lasted for 21-22 days.

Pseudopregnancy was induced by electrical stimulation of the cervix at pro-oestrus and oestrus as reported earlier (Welschen et al., 1975). Since the second electrical stimulation of the cervix was done at oestrus, no rat was killed on that day which should be Day 1 of pseudopregnancy. Duration of pseudopregnancy was 12-14 days, and rats killed at Day 14 or 15 were divided into two groups: a group that had not yet ovulated and a group that had already ovulated, as judged by the presence of newly formed corpora lutea in the histological sections. The day of dioestrus 1 (= metoestrus) was designated as Day 2 of pseudopregnancy. The pregnant and pseudopregnant rats were killed on various days as shown in Tables 1 and 2, respectively. The ovaries were taken out, immediately fixed in Bouin's fluid and embedded in paraffin wax after routine histological procedures. Serial sections of $10 \mu \mathrm{m}$ thickness were stained with haematoxylin and eosin. In one ovary of each animal, follicles $\geq 100 \times 10^{5} \mu \mathrm{m}^{3}$ or mean diameter $\geq 275 \mu \mathrm{m}$, were measured and categorized as non-atretic or atretic as reported earlier (Osman, 1985). They were classified in several volume classes as shown in Tables 1 and 2 with the corresponding mean diameters.

Atretic follicles were also categorized in several stages as used by Osman (1985), i.e. Stage I if degenerative changes were present only in the granulosa wall, either localized in small areas (Ia) or generalized (Ib), and Stage II if changes also involved the oocyte which was either still surrounded by granulosa cells or their remnants (IIa) or was naked (IIb) (see, for details, Osman, 1985).

Since observations of the ovaries were made with a time-lapse of one or more days in the present study and not twice daily as for the earlier study of cyclic animals (Osman, 1985), the rate of atresia was defined as the percentage of atretic follicles, A, in the Stages Ia plus Ib, instead of only those in Stage $\mathrm{Ia}$, in the follicle population consisting of $\mathrm{A}$ and the non-atretic follicles, $\mathrm{N}$, i.e. rate of atresia $=\mathrm{A} /(\mathrm{A}+\mathrm{N}) \times 100 \%$. Follicles in the advanced stages of atresia were excluded since more than $24 \mathrm{~h}$ were needed for an atretic follicle to reach that stage (Osman, 1985). Such follicles could therefore not be used as an actual indicator for the rate of atresia. Except for the whole follicle population, the atretic rate was also calculated for the various volume classes of follicles. Values are given as mean \pm s.d. The Wilcoxon two-sample test (Wilcoxon, 1945) was used for statistical analysis of the results. A difference was considered significant if $P \leq 0.05$. 


\section{Results}

\section{Pregnant rats}

Follicular growth (Table 1). In the first half (=10 days) of pregnancy no significant changes were found in the total number of follicles (non-atretic and atretic) $\geq 100 \times 10^{5} \mu \mathrm{m}^{3}$ ( $=$ diam. $\geq 275 \mu \mathrm{m}$ ). The total number of non-atretic follicles decreased from Days 5-7 to Days 9-11, without significant change in the total number of atretic follicles. Growth into the largest volume, class 5 (usually occupied only at pro-oestrus by about 5 follicles in cyclic animals), for convenience called the class of preovulatory follicles, was noticed from Day 4 to Days 5-7. At Days 9-11, the number of preovulatory follicles decreased again, but no fresh corpora lutea were observed in the histological sections. From Days 9-11 to Days 13-15, there was a significant increase in number of follicles in the whole population due to an increase in the number of atretic follicles, and a further decrease in the number of preovulatory follicles. From Days 17-19 onwards, the same total number of non-atretic follicles as observed at Days 5-7 and earlier, was found. Preovulatory follicles increased in number from Days 13-15 to Days 17-19 and 21 (day of parturition), and achieved the full number of 5 follicles normally found in cyclic animals.

The pool of small antral follicles in volume class 1 , normally maintained in cyclic animals (Osman, 1985), consisted in pregnant rats of 3-8 follicles on the observed days with a mean

Table 1. Mean number \pm s.d. of follicles per ovary in the various volume classes $\geq 100 \times 10^{5} \mu \mathrm{m}^{3}$ (mean diameter in parentheses) during pregnancy in the rat

\begin{tabular}{|c|c|c|c|c|c|c|}
\hline \multirow[b]{2}{*}{$\begin{array}{l}\text { Day of } \\
\text { pregnancy } \\
\text { (no. of } \\
\text { animals) }\end{array}$} & \multicolumn{6}{|c|}{ Volume class $\left(10^{5} \mu \mathrm{m}^{3}\right)$} \\
\hline & $\begin{array}{c}1 \\
100-199 \\
(275-335 \mu \mathrm{m})\end{array}$ & $\begin{array}{c}2 \\
200-349 \\
(336-405 \mu \mathrm{m})\end{array}$ & $\begin{array}{c}3 \\
350-499 \\
(406-455 \mu \mathrm{m})\end{array}$ & $\begin{array}{c}4 \\
500-999 \\
(456-575 \mu \mathrm{m})\end{array}$ & $\begin{array}{c}5 \\
\geq 1000 \\
(\geq 576 \mu \mathrm{m})\end{array}$ & $\begin{array}{l}\text { Total } \\
\text { no.* }\end{array}$ \\
\hline $1(4)$ & $8 \cdot 5 \pm 1 \cdot 3$ & $5 \cdot 5 \pm 1 \cdot 0$ & $1 \cdot 7 \pm 1 \cdot 0$ & $2 \cdot 0 \pm 0 \cdot 8$ & 0 & $\begin{array}{c}17.7 \pm 1.0 \\
(7.7 \pm 1.9)\end{array}$ \\
\hline $2(5)$ & $5 \cdot 0 \pm 2 \cdot 6$ & $6 \cdot 2 \pm 3 \cdot 2$ & $3 \cdot 0 \pm 1.0$ & $4 \cdot 0 \pm 3 \cdot 1$ & $0.2 \pm 0.4$ & $\begin{array}{c}18.4 \pm 6 \cdot 3 \\
(6 \cdot 2 \pm 4 \cdot 3)\end{array}$ \\
\hline $3(4)$ & $6.8 \pm 2.9$ & $3.8 \pm 1.5$ & $2.5 \pm 1.7$ & $3 \cdot 8 \pm 2 \cdot 8$ & $1.0 \pm 1.4$ & $\begin{array}{c}17 \cdot 8 \pm 6 \cdot 2 \\
(12 \cdot 8 \pm 2 \cdot 9)\end{array}$ \\
\hline $4(5)$ & $5 \cdot 6 \pm 3 \cdot 6$ & $3 \cdot 2 \pm 2 \cdot 3$ & $1.8 \pm 1.9$ & $4 \cdot 8 \pm 2 \cdot 0$ & $2 \cdot 0 \pm 1 \cdot 2$ & $\begin{array}{c}17 \cdot 4 \pm 5 \cdot 9 \\
(11.6 \pm 2 \cdot 7)\end{array}$ \\
\hline $5-7 \quad(4)$ & $3 \cdot 2 \pm 1 \cdot 7$ & $3 \cdot 7 \pm 1 \cdot 0$ & $3.0 \pm 0.8$ & $3.0 \pm 1.6$ & $5 \cdot 5 \pm 1.0 \dagger$ & $\begin{array}{c}18.5 \pm 2.5 \\
(12.7 \pm 2.9)\end{array}$ \\
\hline $9-11(8)$ & $3 \cdot 6 \pm 2 \cdot 1$ & $1.7 \pm 1.9$ & $1 \cdot 7 \pm 1 \cdot 2$ & $3 \cdot 1 \pm 1 \cdot 1$ & $2 \cdot 2 \pm 1 \cdot 4 \dagger$ & $\begin{array}{r}12.5 \pm 3 \cdot 6 \ddagger \\
(16.2 \pm 3 \cdot 6)\end{array}$ \\
\hline $13-15(8)$ & $4 \cdot 7 \pm 2 \cdot 5$ & $4 \cdot 0 \pm 2 \cdot 6$ & $2 \cdot 4 \pm 2 \cdot 0$ & $5 \cdot 2 \pm 1 \cdot 9$ & $0.1 \pm 0.4 \dagger$ & $\begin{array}{c}16 \cdot 5 \pm 4 \cdot 5 \\
(25 \cdot 6 \pm 4 \cdot 4) \dagger\end{array}$ \\
\hline $17-19(8)$ & $5 \cdot 5 \pm 2 \cdot 4$ & $4.4 \pm 1.4$ & $2.6 \pm 1.9$ & $5 \cdot 7 \pm 2 \cdot 2$ & $1.0 \pm 0.8 \ddagger$ & $\begin{array}{c}19 \cdot 2 \pm 6 \cdot 1 \\
(27 \cdot 0 \pm 2 \cdot 4)\end{array}$ \\
\hline $21 \S \quad(8)$ & $5 \cdot 7 \pm 2 \cdot 5$ & $2 \cdot 9 \pm 1 \cdot 7$ & $0 \cdot 6 \pm 1 \cdot 4$ & $1 \cdot 7 \pm 2 \cdot 0$ & $5 \cdot 2 \pm 2 \cdot 3 \dagger$ & $\begin{array}{c}16 \cdot 2 \pm 3 \cdot 2 \\
(31 \cdot 1 \pm 5 \cdot 8)\end{array}$ \\
\hline
\end{tabular}

* Total no. of atretic follicles in parentheses.

$\S$ Day of parturition.

+ Significantly different from previous value, $P \leqslant 0.02$.

$\ddagger$ Significantly different from previous value, $P \leqslant 0.05$. 


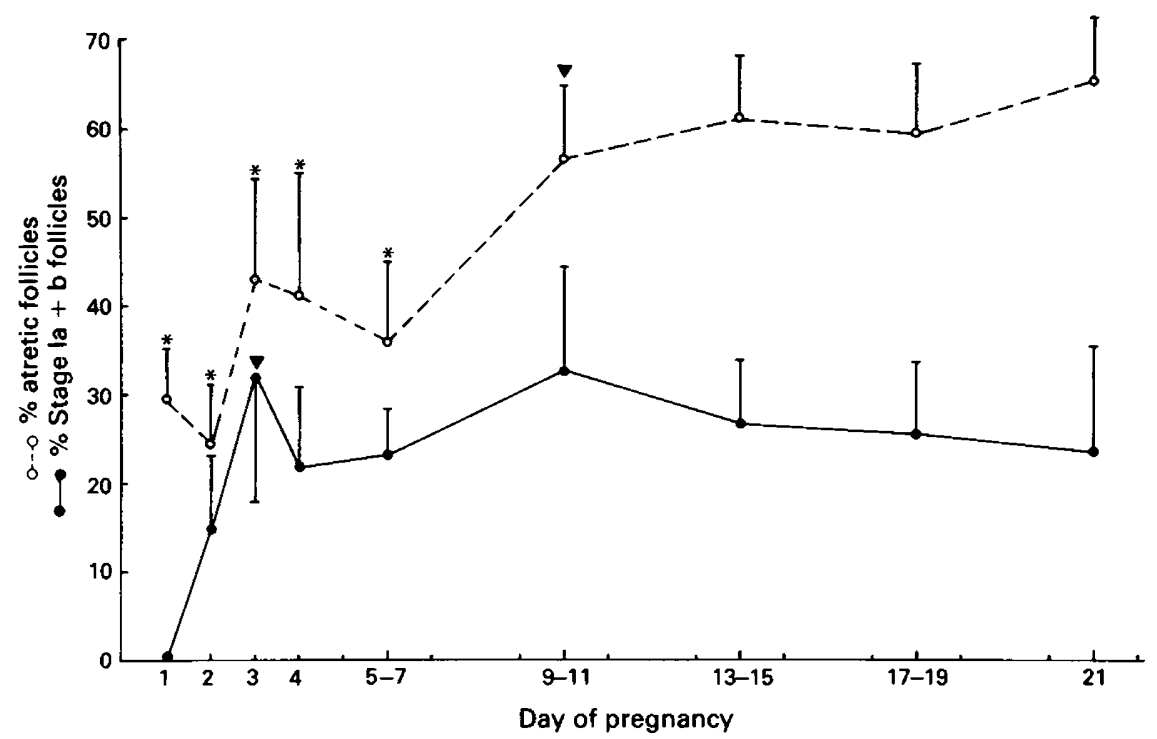

Fig. 1. Percentages of atretic follicles $\left(\mathrm{O}_{--} \mathrm{O}\right)$ of all stages in the follicle population $\geq 100 \times 10^{5} \mathrm{~mm}^{3}$ in pregnant rats, and the rate of atresia (- expressed by the percentage of Stage $I(a+b)$ atretic follicles in the follicle population $\geq 100 \times 10^{5} \mu^{3}$, from which the follicles in advanced stages of atresia II $(a+b)$ are excluded. Vertical bars indicate s.d. $\boldsymbol{\nabla}$, Significantly different from previous value(s), $P<0.05 ;{ }^{*}$, significantly different from values at end of pregnancy: $P \leqslant 0.05$.

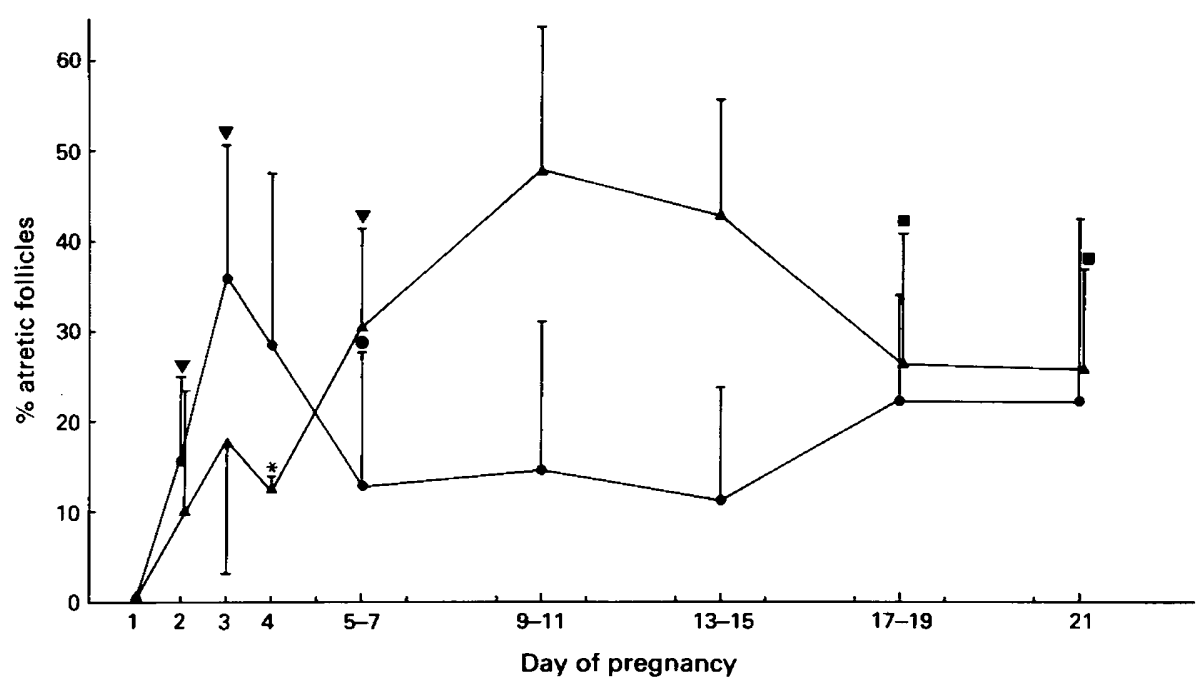

Fig. 2. Rates of atresia in the growing classes follicles in the follicle population $\geq 100 \times 10^{5} \mu \mathrm{m}^{3}$ in pregnant rats. Vertical bars indicate s.d. $\nabla$, Significantly different from previous value, $P<0.02$;, significantly different from value at Day $3, P=0.02 ;{ }^{*}$, significantly different from value at Day $1, P<0.02 ; \mathbf{\square}$, significantly different from value at Day $9-11, P<0.02$. 
number \pm s.d. of $5.4 \pm 1.6$ during the whole pregnancy which is about half of the mean number, i.e. $11 \cdot 3 \pm 5 \cdot 0$, found in a normal cycle. Ovulation was not observed in the females on the day of parturition.

Follicular atresia. The atretic portion, consisting of atretic follicles in the early $(\mathrm{Ia}+\mathrm{Ib})$ and the advanced stages (IIa $+\mathrm{IIb}$ ), in the follicle population $\geq 100 \times 10^{5} \mu^{3}$ (Fig. 1) fluctuated between 25 and $42 \%$ from Day 1 to Days 5-7, increased at Days $9-11$ above 50\% and was about $65 \%$ at the end of pregnancy. The rate of atresia in the follicle population (Fig. 1) increased during the first days of pregnancy from 0 to $30 \%$ and remained at a mean level of $26 \cdot 5 \pm 4 \cdot 5 \%$ from Day 4 until the end of pregnancy. The rate of atresia in the various classes of follicles is presented in Fig. 2 . Since follicles in the volume classes $1-3$, for convenience called growing follicles, showed identical profiles in rates of atresia, they were put together in one group in the diagram for clarity of presentation. The same was done for follicles of classes 4 and 5 , for convenience referred to as maturing follicles. The rate of atresia in the class of growing follicles increased from 0 to $\sim 32.5 \%$ in the first

Table 2. Mean number \pm s.d. of follicles per ovary in the various volume classes $\geq 100 \times 10^{5} \mu \mathrm{m}^{3}$ during pseudopregnancy in the rat

\begin{tabular}{|c|c|c|c|c|c|c|}
\hline \multirow{2}{*}{$\begin{array}{l}\text { Day of } \\
\text { pseudo- } \\
\text { pregnancy } \\
\text { (no. of } \\
\text { animals) }\end{array}$} & \multicolumn{6}{|c|}{ Volume class $\left(10^{5} \mu \mathrm{m}^{3}\right)$} \\
\hline & $\stackrel{1}{100-199}$ & $\begin{array}{c}2 \\
200-349\end{array}$ & $\begin{array}{c}3 \\
350-499\end{array}$ & $\begin{array}{c}4 \\
500-999\end{array}$ & $\begin{array}{c}5 \\
\geq 1000\end{array}$ & $\begin{array}{c}\text { Total } \\
\text { no.* }\end{array}$ \\
\hline $2(7)$ & $5 \cdot 9 \pm 2 \cdot 4$ & $9 \cdot 4 \pm 2 \cdot 8$ & $6 \cdot 0 \pm 2 \cdot 8$ & $2 \cdot 4 \pm 1 \cdot 6$ & 0 & $\begin{array}{l}23 \cdot 7 \pm 4 \cdot 7 \\
(8 \cdot 6 \pm 4 \cdot 0)\end{array}$ \\
\hline $3(7)$ & $8 \cdot 3 \pm 2 \cdot 1$ & $7 \cdot 4 \pm 3 \cdot 4$ & $2 \cdot 4 \pm 1 \cdot 5$ & $5 \cdot 7 \pm 2 \cdot 3$ & 0 & $\begin{array}{c}24 \cdot 1 \pm 2 \cdot 5 \\
(20 \cdot 7 \pm 6 \cdot 1) \dagger\end{array}$ \\
\hline $4(7)$ & $5 \cdot 6 \pm 2 \cdot 8$ & $3 \cdot 6 \pm 2 \cdot 0$ & $0 \cdot 7 \pm 1 \cdot 1$ & $4 \cdot 3 \pm 1 \cdot 3$ & $1 \cdot 4 \pm 1 \cdot 3$ & $\begin{array}{r}15.9 \pm 3.5 \dagger \\
(21.0 \pm 11 \cdot 2)\end{array}$ \\
\hline $5(7)$ & $5 \cdot 1 \pm 3 \cdot 5$ & $5 \cdot 7 \pm 2 \cdot 4$ & $2 \cdot 1 \pm 1 \cdot 2$ & $4 \cdot 6 \pm 3 \cdot 0$ & $2 \cdot 3 \pm 1 \cdot 5$ & $\begin{array}{c}19 \cdot 9 \pm 4 \cdot 7 \\
(18 \cdot 1 \pm 5 \cdot 6)\end{array}$ \\
\hline $6(5)$ & $5 \cdot 2 \pm 3 \cdot 7$ & $4 \cdot 8 \pm 2 \cdot 6$ & $1 \cdot 2 \pm 1 \cdot 1$ & $2 \cdot 6 \pm 1 \cdot 7$ & $0.8 \pm 1 \cdot 1 \ddagger$ & $\begin{array}{c}14 \cdot 6 \pm 3 \cdot 2 \ddagger \\
(13 \cdot 4 \pm 2 \cdot 7)\end{array}$ \\
\hline $7(5)$ & $6 \cdot 6 \pm 2 \cdot 3$ & $4 \cdot 6 \pm 1 \cdot 3$ & $2 \cdot 0 \pm 1 \cdot 6$ & $4 \cdot 8 \pm 1 \cdot 3$ & $1 \cdot 4 \pm 1 \cdot 1$ & $\begin{array}{c}19 \cdot 4 \pm 3 \cdot 1 \\
(22 \cdot 0 \pm 2 \cdot 1) \dagger\end{array}$ \\
\hline $8(5)$ & $3 \cdot 8 \pm 1 \cdot 1$ & $2 \cdot 0 \pm 1 \cdot 2$ & $1 \cdot 8 \pm 2 \cdot 2$ & $2 \cdot 2 \pm 1 \cdot 5$ & $1 \cdot 4 \pm 1 \cdot 1$ & $\begin{array}{c}11 \cdot 2 \pm 2 \cdot 5 \dagger \\
(15 \cdot 0 \pm 4 \cdot 4) \ddagger\end{array}$ \\
\hline $9(6)$ & $6 \cdot 7 \pm 2 \cdot 3$ & $4 \cdot 5 \pm 2 \cdot 6$ & $2 \cdot 3 \pm 1 \cdot 5$ & $4 \cdot 0 \pm 1 \cdot 7$ & $1 \cdot 0 \pm 1 \cdot 1$ & $\begin{array}{c}18.5 \pm 3.9 \dagger \\
(21.2 \pm 7 \cdot 7)\end{array}$ \\
\hline $11(6)$ & $4 \cdot 8 \pm 2 \cdot 0$ & $3.5 \pm 1 \cdot 2$ & $1 \cdot 8 \pm 1 \cdot 7$ & $2.7 \pm 1.9$ & $1.8 \pm 1.6$ & $\begin{array}{c}14 \cdot 7 \pm 4 \cdot 0 \\
(22 \cdot 8 \pm 4 \cdot 2)\end{array}$ \\
\hline $13(5)$ & $5 \cdot 2 \pm 1 \cdot 5$ & $2 \cdot 0 \pm 1 \cdot 6$ & $0.2 \pm 0.4$ & $3 \cdot 6 \pm 1 \cdot 3$ & $4 \cdot 0 \pm 1 \cdot 4$ & $\begin{array}{c}15 \cdot 0 \pm 3 \cdot 4 \\
(25 \cdot 0 \pm 5 \cdot 6)\end{array}$ \\
\hline $\begin{array}{l}14-15 \\
\text { No ovulation } \\
\text { (6) }\end{array}$ & $3 \cdot 0 \pm 0 \cdot 9$ & $1 \cdot 5 \pm 1 \cdot 2$ & $0.2 \pm 0.4$ & $2 \cdot 2 \pm 1 \cdot 8$ & $3 \cdot 0 \pm 2 \cdot 3$ & $\begin{array}{r}9 \cdot 8 \pm 2 \cdot 4 \dagger \\
(26 \cdot 7 \pm 5 \cdot 6)\end{array}$ \\
\hline $\begin{array}{l}\text { Ovulation } \\
\text { (7) }\end{array}$ & $7 \cdot 0 \pm 3 \cdot 3$ & $6 \cdot 0 \pm 1 \cdot 0$ & $1 \cdot 9 \pm 1 \cdot 2$ & $1 \cdot 1 \pm 1 \cdot 1$ & 0 & $\begin{array}{c}16 \cdot 0 \pm 2 \cdot 9 \\
(20 \cdot 3 \pm 6 \cdot 1)\end{array}$ \\
\hline
\end{tabular}

* Total no. of atretic follicles in parentheses.

$\dagger$ Significantly different from previous value, $P \leqslant 0.02$.

$\ddagger$ Significantly different from previous value, $P \leqslant 0.05$. 
2 days of pregnancy, decreased thereafter to $10-15 \%$ at Days 5-7, 9-11 and 13-15, and was $\sim 22.5 \%$ during the last 6 days of gestation. The rate of atresia in the maturing follicles increased to $\sim 12 \%$ in the first 3 days, increased further to $30 \%$ at Days 5-7, was between 40 and $50 \%$ at Days 9 to 15 and decreased to $\sim 26 \%$ at Days $17-19$ and at end of pregnancy.

The distribution of atretic follicles in the various stages of atresia did not show marked changes for the Stages Ia, Ib and IIa, but an accumulation of atretic follicles in Stage IIb was apparent towards the end of pregnancy. The number of IIb-atretic follicles started to increase from $2.7 \pm 2.5$ at Days 5-7, to 6.7 \pm 1.7 at Days 9-11 $(P<0.05)$, and increased further to $17.7 \pm 2.6$ at Days $13-15$ $(P<0.02$ as compared to Days $9-11)$, to remain at that level until the end of pregnancy. These follicles belonged to the volume classes $1-3$; few or none belonged to volume classes 4 and 5 .

\section{Pseudopregnant rats}

Follicular growth (Table 2). The total number of follicles (non-atretic and atretic follicles) $\geq 100 \times 10^{5} \mu \mathrm{m}^{3}$ ( = diam. $\left.\geq 275 \mu \mathrm{m}^{3}\right)$ increased from Day 2 to Day $3(P=0.02)$, which was due to an increase in the atretic portion. From Day 4 to Day 5 no significant change was found although there was a slight increase in the number of non-atretic follicles which, however, dropped again at Day 6. The total number of atretic follicles was also low at Day 6 and significantly less as compared to the first increase at Day $3(P<0.05)$. At Day 7 the total number of follicles (non-atretic and atretic) increased again $(P<0.02)$ mainly due to an increase in the number of atretic follicles. At Day 8 the numbers of both types of follicles decreased $(P<0.02)$ as compared to those at Day 7. But at Day 9 numbers of non-atretic and atretic follicles comparable to those of Day 7 were reached again and no further change was noted until the end of pseudopregnancy. At Days 14-15, the number of non-atretic follicles in animals without ovulation decreased significantly as compared to that in animals at Day 13. In animals that had ovulated, the total numbers of both types of follicles did not change as compared to that at Day 13 , but changes were noted in the numbers of follicles in the various volume classes: a decrease in the number of maturing follicles (classes 4 and 5) was compensated by increase in number of growing follicles (classes 1-3) after ovulation. Preovulatory follicles (volume class 5) were found from Day 4 onwards but, in contrast to pregnant rats, their number never reached the number of ovulating follicles in cyclic animals. A decrease in number was found from Day 5 to Day $6(P<0.05)$, but no fresh corpora lutea were observed in the sections. After Day 6 the number of preovulatory follicles remained constant until Day 13 when 4 follicles emerged $(P<0.02$ compared with Day 6$)$.

The number of ovulations in 7 rats after pseudopregnancy was $5.0 \pm 1.6$ as judged by the count of newly formed corpora lutea in the histological sections. Only 3 animals showed, respectively, 2, 4 and 6 fresh corpora lutea which were all of the same age, i.e. that of corpora lutea from the morning of vaginal oestrus, while the other 4 animals had corpora lutea of two different ages, i.e. that of oestrous and of dioestrous 1 animals (Fig. 3). Two rats, one with only dioestrous 1 and the other with dioestrous 1 and dioestrous 2 corpora lutea, were discarded. The pool of small antral follicles in volume class 1 consisted of 4-8 follicles on the observed days with a mean number \pm s.d. of $5.7 \pm 1.2$ during the 12 days of pseudopregnancy, and was still within that range in animals that had ovulated.

Follicular atresia. The atretic portion, consisting of all stages of atresia, was $25 \%$ of the whole follicle population $\geq 100 \times 10^{5} \mu^{3}$ (Fig. 4) at Day 2 of pseudopregnancy, increased significantly at Day 3 to $45 \%$. From Day 3 to Day 9 , the percentages fluctuated insignificantly between 45 and $57 \%$. Higher percentages were found at Days 11 and 13 and in the ovaries of animals that had not ovulated at Days 14-15 as compared to the first increase at Day 3. In animals that had ovulated, the percentage of the atretic portion indicated a decrease which was not statistically different from that at Day 13, and was about the same level as that of Day 9.

The rate of atresia in the follicle population $\geq 100 \times 10^{5} \mu^{3}$ (Fig. 4) increased significantly 


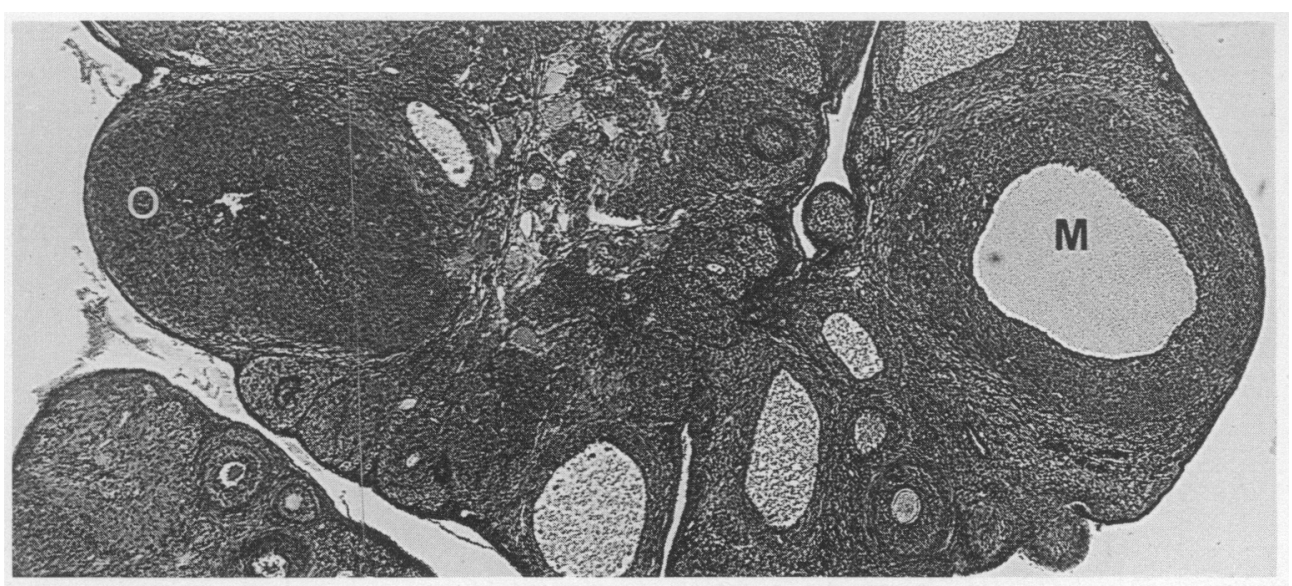

Fig. 3. Section of a rat ovary at the end of pseudopregnancy (Day 15), showing two types of corpora lutea, one $(\mathrm{O})$ originating from recent ovulation (as usually seen on the morning of vaginal oestrus), and the other (M) from ovulation $24 \mathrm{~h}$ earlier (as usually seen at dioestrus $1) . \times 50$.

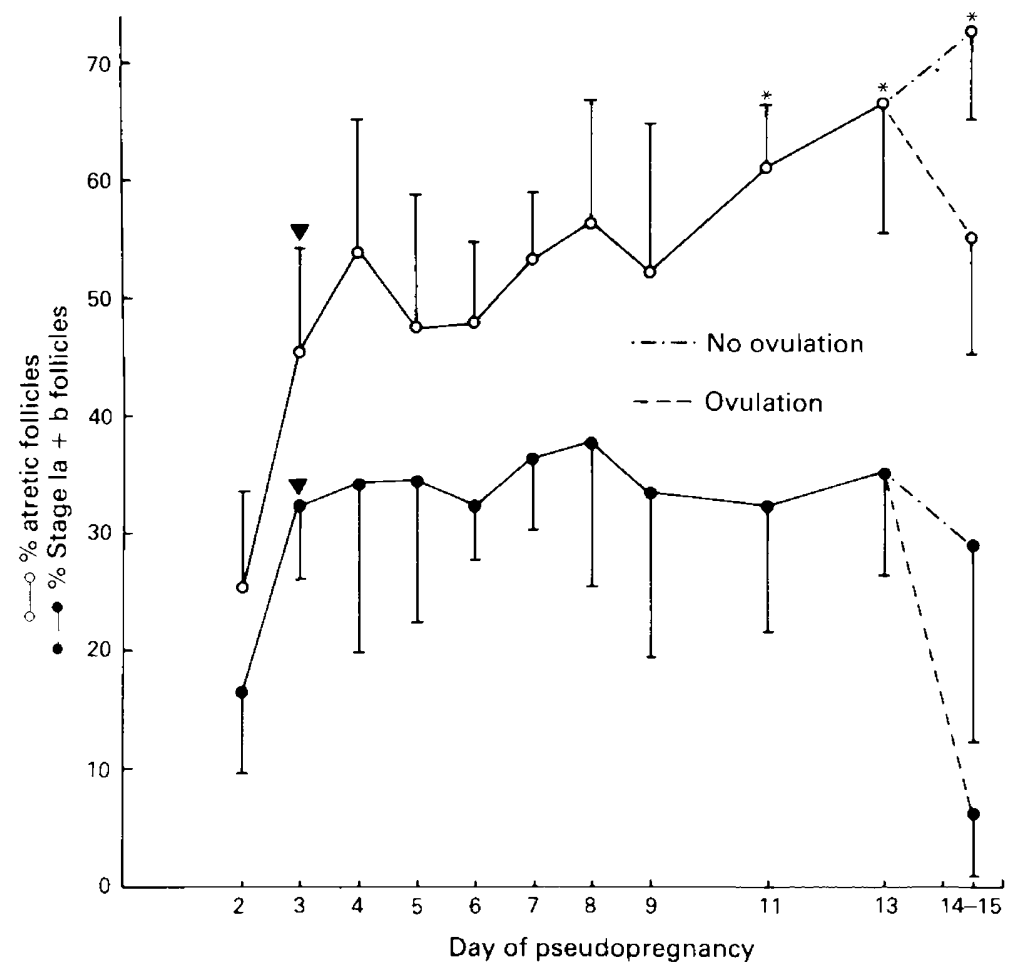

Fig. 4. Percentage $(\mathrm{O}-\mathrm{O})$ and rate of atresia $(-\infty)$ in the follicle population $\geq 100 \times 10^{5} \mu \mathrm{m}^{3}$ in pseudopregnant rats. Vertical bars indicate s.d. $\boldsymbol{\nabla}$. Significantly different from previous value, $P<0.02$; , significantly different from value at Day $2, P<0.02$. 


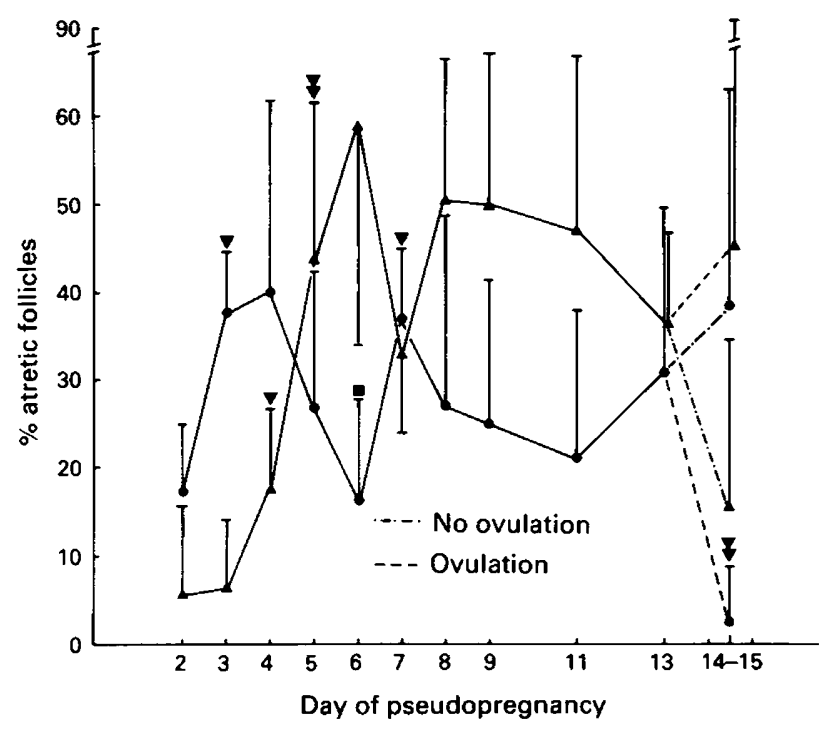

Fig. 5. Rates of atresia in the growing $\left(-\frac{-}{-}\right)$ and maturing $(\Delta-\Delta)$ classes of follicles in the follicle population $\geq 100 \times 10^{5} \mu \mathrm{m}^{3}$ in pseudopregnant rats. Vertical bars indicate s.d. $\boldsymbol{\nabla}$, Significantly different from previous value, $P<0.02 ; \boldsymbol{\square}$, significantly different from value at Day $2, P<0.02 ; 7$, significantly different from previous value, $P<0.05$.

from $16.5 \%$ at Day 2 to $32 \%$ at Day 3 and remained between 32 and $37 \%$, until Day 13 in animals that had not ovulated. In animals that had ovulated the rate of atresia decreased to $7.5 \%$ which was lower than that at Day $2(P<0.02)$, but of the same level as in cyclic animals $($ Osman, 1985). The rate of atresia in the classes of growing follicles (Fig. 5) increased from $17.5 \%$ at Day 2 of pseudopregnancy to $37.5 \%$ at Day 3 , had decreased at Day $6(P<0.02)$, but increased again at Day $7(P<0.02$ as compared to Day 6$)$ and did not change until Day 13. In animals that had not ovulated the rate of atresia did not change, but in animals that had ovulated, the rate decreased significantly and was even less than at Day 2 of pseudopregnancy $(P<0.02)$. The rate of atresia in the classes of maturing follicles increased from Day 3 to Day 4 and increased further at Day 5; it remained still high but not significant at Day 6 and decreased at Day $7(P<0.02)$ as compared to Day 5. No significant change was found thereafter until Day 13 in animals that had ovulated. In animals that had not ovulated a decrease in the rate of atresia was statistically not significant as compared to the rate at Day 13 , but differed significantly from the rates at Day $5(P<0.05)$, Day 6 , Days 8-11 (all $P<0 \cdot 02$ ).

As in pregnant rats, no changes were found in the distribution of the atretic follicles in the various stages of atresia Ia, Ib and IIa (data not shown). However, accumulation of stage IIb atretic follicles was apparent after the first week of pseudopregnancy. The number of atretic follicles in Stage IIb was $3.4 \pm 1.7$ at Day 8 , increased to $8.8 \pm 2.7(P<0.02)$ at Day 11 and increased further to $15.2 \pm 3.5(P<0.02$ as compared to Day 11$)$ in animals that had not yet ovulated at Day 14-15. In animals that had ovulated the number had not significantly changed as compared to Day 11 . Atretic follicles in the advanced stage IIb also belonged to volume classes $1-3$, and few or none to volume classes 4 and 5 .

\section{Histology}

Histological observations did not reveal differences in morphological changes during follicular 
atresia in pregnant and pseudopregnant rats as compared to those observed in cyclic rats. Collapsed large follicles, i.e. disrupted follicles without an antrum, with a crumpled or folded granulosa wall (Figs 6-9), mostly derived from preovulatory follicles, were observed in ovaries of pregnant rats at Day 9 of gestation and in those of pseudopregnant rats at Days 6,8 and 9 of pseudopregnancy. A few follicles had expelled their oocytes into the ovarian interstitium (Fig. 6); in
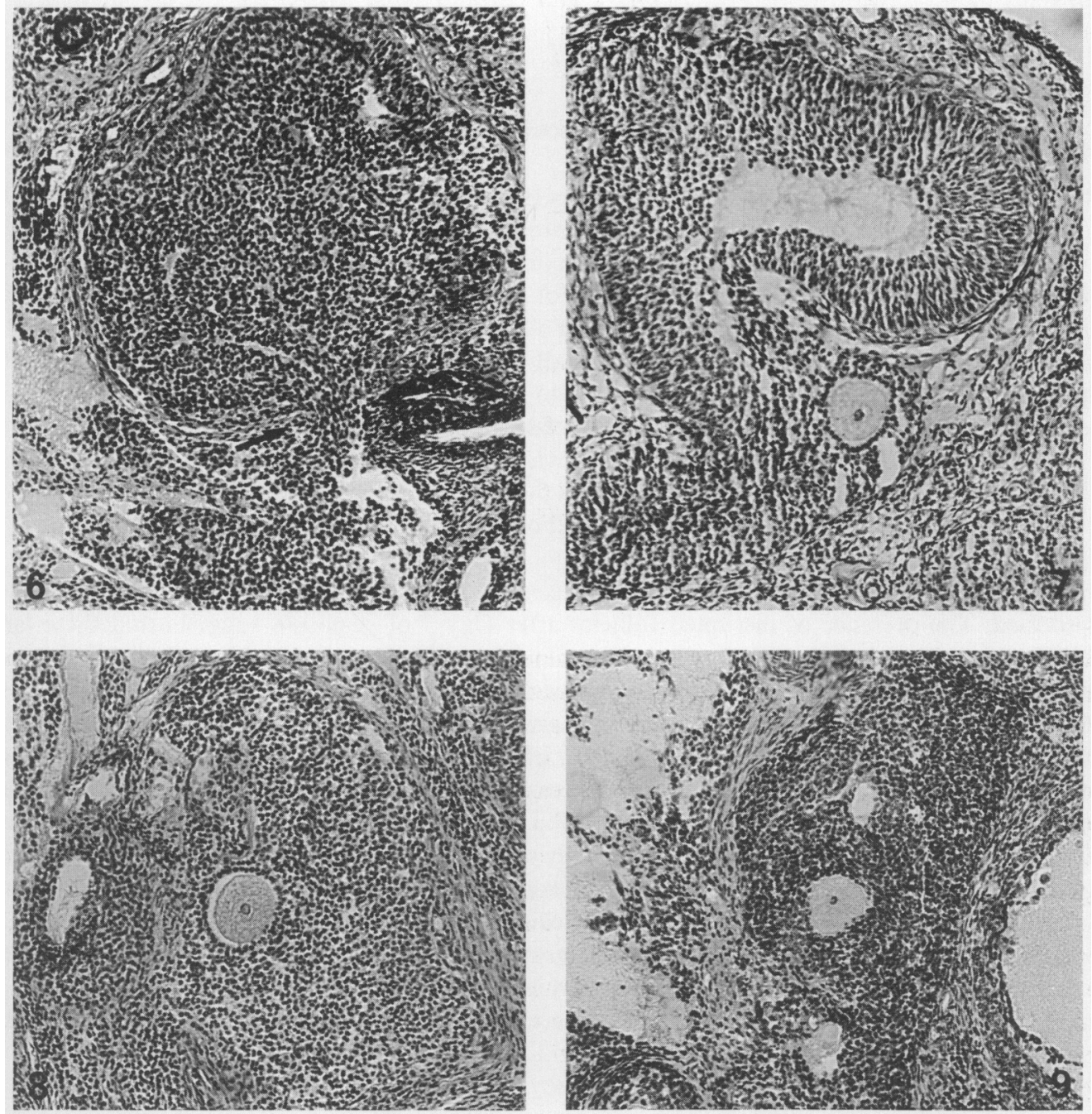

Fig. 6. Collapsed follicle with stigma (arrow) in an ovary of a pseudopregnant rat at Day 7. 'T he oocyte was found in the interstitium 25 sections away. $\times 125$.

Fig. 7. Collapsing follicle with folded granulosa wall and the oocyte (in germinal stage) displaced at the periphery of the follicle. Ovary of a pseudopregnant rat at Day $7 . \times 125$.

Fig. 8. Oocyte amidst complete collapsed degenerated granulosa wall in an ovary of a pseudopregnant rat at Day $7 . \times 125$.

Fig. 9. Oocyte amidst crumpled granulosa wall with advanced degenerated cells showing pycnotic nuclei. Ovary of a pregnant rat at Day $9 . \times 125$. 
most collapsed follicles the oocytes were found amidst the folded granulosa walls (Figs 7-9). In some collapsed follicles a stigma had been formed at the ovarian surface. These follicles had probably released their oocytes outside the ovary since no oocytes were found in the surrounding tissue. All oocytes observed in the collapsed follicles or released into the ovarian interstitium were in the germinal vesicle stage. Cystic follicles, i.e. follicles with a large antrum and thin granulosa wall consisting of 1 or 2 layers of granulosa cells comparable to those observed in rats reared in constant light (Lawton \& Schwartz, 1967), and corpora lutea with a trapped ovum were only occasionally observed.

\section{Discussion}

Rhythmic follicular maturation representing a persistence of the 5-day pattern of the oestrous cycle as suggested by Evans \& Swezy (1931) and Bujard (1953) could not be demonstrated in rat ovaries during pregnancy and pseudopregnancy in the present study. This is in accord with Greenwald's observations (1966) in which he also could not find any quantitative evidence for a wave-like development of large follicles in pregnant rats. Follicular development during gestation observed in the present study also does not differ essentially from that observed by Greenwald (1966) for Sprague-Dawley rats. The follicles developing to preovulatory size in ovulation numbers at Days 5-7 in pregnant rats were derived from a pool of small antral follicles that had been exposed to an FSH surge 5 days before as suggested by Bogovich, Richards \& Reichert (1981) and are comparable to those follicles that normally ovulate in 5-day cyclic animals. In an earlier report, Osman (1985) suggested that the follicles that ovulate at oestrus in cyclic animals are already present at an antral stage in the previous cycle.

The fate of the preovulatory follicles present in early pregnancy has not been previously described. The presence of disrupted follicles after Day 7 of gestation suggests that these large follicles have degenerated and collapsed since there is no LH surge during this period; LH secretion was found to be low throughout the gestation period in rats (Greenwald, 1966; Morishige, Pepe \& Rothchild, 1973). The germinal vesicle stage in which the oocytes were found, in or outside the collapsed follicles, also suggests lack of effective LH stimulation, in contrast to the oocytes released into the ovarian interstitium, which resumed meiosis in indomethacin-treated rats in which the LH surge was not inhibited (Osman \& Dullaart, 1976). The preovulatory follicles observed in ovulation numbers at the end of pregnancy were probably derived from a pool of antral follicles which had not been previously exposed to a FSH surge. Nevertheless, this pool of follicles seemed able to produce the normal number of preovulatory follicles at end of pregnancy. A low tonic secretion of LH is assumed to cause this dioestrous follicular growth (Bogovich et al., 1981). It is not within the scope of this quantitative morphological study to discuss the hormonal situation in relation to follicular development in rats in the pregnant state, since this has already been extensively discussed by Schwartz \& Tally (1968).

In contrast to the situation during pregnancy, no complete numbers of preovulatory follicles were observed during pseudopregnancy, neither at Day 5 nor at the end of pseudopregnancy. This difference in follicular growth in pregnant and pseudopregnant rats cannot be explained at present; FSH, LH and prolactin secretions in pseudopregnant rats do not seem to differ from those in pregnant rats on the corresponding days (Greenwald, 1966; de Greef, Dullaart \& Zeilmaker, 1977; Morishige et al., 1973). Notwithstanding the incomplete numbers of preovulatory follicles, a full number of ovulations were seen at the end of pseudopregnancy as judged by the number of fresh corpora lutea in the histological sections. The different ages of the corpora lutea, however, suggest the possibility of two successive series of ovulations at the end of pseudopregnancy between Days 13 and 15 .

The continuous presence of antral follicles of all sizes throughout pregnancy and pseudopregnancy observed in the present study is in agreement with earlier reports by Greenwald 
(1966) and Welschen et al. (1975) respectively. The presence of follicles does not exclude the possibility of follicular replacements during pregnancy. The rates of atresia shown in the present study reveal continuous partial elimination of all sizes of follicles and refute the possibility of follicular quiescence, i.e. maintenance of non-growing follicles, during the dioestrous period of pregnancy and pseudopregnancy. Continuous initiation of follicular growth was also found in pregnant mice by an autoradiographic method (Pedersen \& Peters, 1971).

The present study also shows that follicles in the advanced stages of atresia which are eliminated through compression by the rapid structural changes in the ovary at pro-oestrus and oestrus in cyclic animals (Osman, 1985), can persist for a long time in a prolonged dioestrus and accumulate at the end of pregnancy and pseudopregnancy. These follicles belonged mostly to the volume classes 1-3, while the larger degenerating follicles collapsed after a few days.

Copulation seemed primarily to reduce the preovulatory gonadotrophin surge-induced formation of a new crop of follicles which normally contains $\sim 20$ small antral follicles of class 1 at oestrus in cyclic animals (Osman, 1985) to $\sim 8$ follicles at the comparable Day 1 of pregnancy. The effect of electrical cervical stimulation on the formation of the new crop of follicles at oestrus (= Day 1), in pseudopregnant rats, could not be shown since no animal was killed on that day. However, since the pool of small antral follicles was also reduced throughout the observed period, to the same extent as that in pregnant rats, a similar reduction of the initial new crop of follicles could also have taken place in pseudopregnant rats. Whether copulation and electrical cervical stimulation reduced the recruitment of antral follicles from preantral stages, could not be concluded from the present study.

The pool of small antral follicles of class 1 , which consists of $\sim 10$ follicles in cyclic animals and which is maintained even when atresia eliminates all other classes of follicles except class 5 (the class of preovulatory follicles) at pro-oestrus (Osman, 1985), was also reduced to only 5-6 follicles in pregnant and pseudopregnant rats. Nevertheless, the small crop of follicles and the pool of antral follicles seemed sufficient to provide: (1) at end of gestation the full number of preovulatory follicles (Table 1) which will ovulate; (2) at end of pseudopregnancy the full number of ovulations, although probably taking place on 2 successive days. Ovulation on two successive days at the end of pseudopregnancy in rats, has never been reported before and should be investigated further.

I thank Mrs C. Lieuwma-Noordanus and Mr H. J. van der Heyden for histo-technical work and Mrs E. Klink for typing the manuscript.

\section{References}

Asami, G. (1920) Observations on the follicular atresia in the rabbit ovary. Anat. Rec. 18, 323-344.

Bogovich, K., Richards, J.S. \& Reichert, L.E., Jr (1981) Obligatory role of luteinizing hormone (LH) in the initiation of preovulatory follicular growth in the pregnant rat: Specific effects of human chorionic gonadotropin and follicle-stimulating hormone on LH-receptors and steroidogenesis in theca, granulosa, and luteal cells. Endocrinology 109, $860-867$.

Bujard, E. (1953) L'ovaire de cobaye. 1. L'ovaire gravide. Rev. Suisse Zool. 60, 615-652.

de Greef, W.J., Dullaart, J. \& Zeilmaker, G.H. (1977) Serum concentrations of progesterone, luteinizing hormone, follicle stimulating hormone and prolactin in pseudopregnant rats: effect of decidualization. Endocrinology 101, 1054-1063.

Evans, H.M. \& Swezy, O. (1931) Ovogenesis and the normal follicular cycle in adult mammalia. Mem. Univ. Calif. 9, 119-225.
Greenwald, G.S. (1966) Ovarian follicular development and pituitary FSH and LH content in the pregnant rat. Endocrinology 79, 572-578.

Greenwald, G.S. (1978) Follicular development during pregnancy. In The Vertebrate Ovary, Ch. 19, pp. 664-676. Ed. R. E. Jones. Plenum Press, New York.

Ingram, D.L. (1962) Atresia. In The Ovary, Vol. 1, Ch. 4, pp. 247-273. Ed. S. Zuckerman. Academic Press, New York.

Lawton, I.E. \& Schwartz, N.B. (1967) Pituitary-ovarian function in rats exposed to constant light: A chronological study. Endocrinology 81, 497-508.

Morishige, W.K., Pepe, G.J. \& Rothchild, I. (1973) Serum luteinizing hormone, prolactin and progesterone levels during pregnancy in the rat. Endocrinology 92, 1527-1530.

Osman, P. (1975) Preovulatory changes in the ovaries during first spontaneous pro-oestrus in the rat. $J$. Endocr. 67, 259-265.

Osman, P. (1985) Rate and course of atresia during 
follicular development in the adult cyclic rat. $J$ Reprod. Fert. 73, 261-270.

Osman, P. \& Dullaart, J. (1976) Intraovarian release of eggs in the rat after indomethacin treatment at prooestrus. J. Reprod. Fert. 47, 101-103.

Pedersen, T. \& Peters, H. (1971) Follicle growth and cell dynamics in the mouse ovary during pregnancy. Fert. Steril. 22, 42-52.

Schwartz, N.B. \& Tally, W.L. (1968) Daily measurement of pituitary LH content during pregnancy in the rat: do cyclic changes persist? J. Reprod. Fert. 15, 39-45.
Welschen, R., Osman, P., Dullaart, J., de Greef, W.J., Uilenbroek, J.Th.J. \& de Jong, F.H. (1975) Levels of follicular-stimulating hormone, luteinizing hormone, oestradiol-17ß and progesterone, and follicular growth in the pseudopregnant rat. J. Endocr. 64, $37-47$.

Wilcoxon, F. (1945) Individual comparisons by ranking methods. Biometrics Bull. 1, 80-83.

Received 19 December 1984 